\section{Adult stem cells: assessing the case for pluripotency}

\section{Catherine M. Verfaillie}

\begin{abstract}
It has been known for decades that stem cells with limited differentiation potential are present in post-natal tissues of mammals, and adult stem cells are already used clinically. For instance, hematopoietic stem cells can reestablish the hematopoietic system following myeloablation, and stem cells are being used to regenerate comeal and skin tissue. But recent studies report that adult tissues might contain cells with pluripotent characteristics. These have evoked significant excitement, given the medical implications, but have also met with much skepticism. Indeed, most studies still await independent confimation, there is a low frequency with which the apparent lineage switching occurs, and importantly such lineage switching defies established developmental biology and stem cell principles. Here, I critically review the published data indicating that postnatal stem cells persist that have greater differentiation potential than previously thought.
\end{abstract}

Published online: 26 September 2002

Stem cells have been defined in many different ways. However, the main principles indude (1) self-renewal, or theability to generate at least one daughter cell with characteristics similar to the initiating cell; (2) multi-lineage differentiation of a singlecell; and (3) and in vivo functional reconstitution of a given tissue [1]. Theembryonic stem (ES) cell, first obtained from mouse [2,3], and more recently from non-human primates and human blastocysts [4,5], fulfills all these principles (Fig. 1). Both mouseand human ES cell-lines have been maintained continuously in culturefor more than $300-400$ cell doublings. ES cells differentiate into all somatic cell types when injected into a blastocyst and form mature progeny cells of all three embryonic germ layers in vitro (embryoid bodies) or in vivo (teratomas). Finally, all differentiated progeny of ES cells arefunctional cells as micegenerated by tetraploid embryo complementation are viable [6].

Most adult stem cells in theory al so fulfill these criteria, even though the degree of self renewal and differentiation potential is less than that seen for ES cells. The best studied adult stem cell, the hematopoietic stem cell (HSC) [7-9], undergoes, at least in vivo, self-renewing cell divisions, differentiates at thesingle cell level intoall mature bl ood el ements and functionally repopulates the hematopoietic system of a myeloablated animal or human. Other adult stem cells have been more recently defined and are thereforeless well studied. However, neural stem cells (NSCs) $[10,11]$, mesenchymal stem cells (MSCs) [12-16] and epidermal stem cells [17] all fulfill these basic criteria. Other cells al sotermed stem cells, such as corneal stem cells [18] and angioblasts or endothelial stem cells [19] fulfill all criteria except that they differentiateintoa singletype of differentiated cell only.

'Stem cell plasticity'is a new term that has been used to describetherecent observations that greater potential might persist in post-natal adult stem cells than previously thought. Thereis yet no consensus on what the definition for such plasticity should be. However, tostrictly definea stem cell with greater plasticity, simpleapplication of the conventional stem cell definition should suffice Then, minimal criteria for a stem cell with plasticity should be (1) self-renewal ability; (2) differentiation of a singlecell into cells of the tissue of origin and into at least one cell type different from thetissue of origin; and (3) functional differentiation in vivo into cells of thetissue of origin and at least onecell type of a tissue other than the tissue of origin. In this review, wewill critically assess studies describing stem cell plasticity in light of this definition.

\section{Studies describing stem cell plasticity}

Over the past five years, at least 50 manuscripts have been published indicating that cells from a given tissue might becapable of differentiating into cells of a different tissue, and thesehavetherefore been placed under the umbrella of stem cell plasticity (Fig. 2). The majority of studies were donein rodent models, while fewer used human cell sources. M ost studies were based on in vivotransplantation of either sex-mismatched cells or genetically marked cells, and detection of donor cells was based on presence of the Y-chromosome or themarker gene. There are excellent reviews of the pitfalls invol ved in detection of donor cells using either marking system $[20,21]$. The majority of studies depended on phenotypic characteristics to definedifferentiation intocells different from the tissue of origin, but haveyet to demonstratethat the cells of thesecond tissuehavefunctional characteristics of that lineage. Finally, in themajority of studies, non-purified populations of cells or cells purified to partial homogeneity weretransplanted, therefore making it impossibleto assess the donal origin of differentiated cells of thetissue of origin and of cells with characteristics of a second tissue. The fol lowing sections will discuss the evidence for stem cell plasticity.

Plasticity of hematopoietic bone marrow cells Morethan $80 \%$ of studies reporting adult stem cell plasticity to date have been performed using bone marrow (BM), or BM or peripheral blood (PB) enriched for HSC. Differentiation not only into hematopoi etic cells but also cells with characteristics of skeletal muscle[22,23], cardiac muscle[24,25], endothelium [26], neuroectoderm [27,28], skin epithelium [29] and endodermal cells [29-31], including hepatocytes, gastrointestinal epithelium and lung epithelium, has been described. 


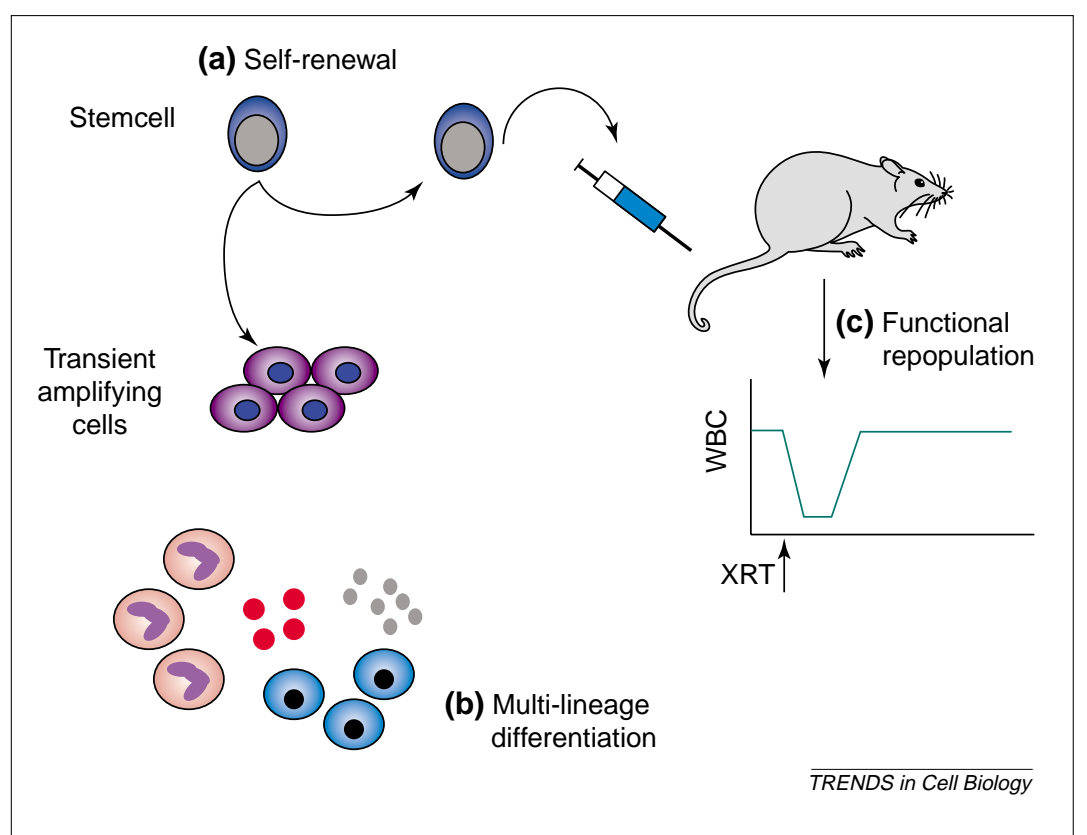

Fig. 1. Stem cell definition. Stem cells are defined as cells that have: (a) self-renewal ability; (b) multi-lineage differentiation ability of a single cell; and (c) show in vivo functional reconstitution of a tissue. This is exemplified here by hematopoietic stem cells (HSCS). HSCs can undergo sequential self-renewing cell divisions, even though this is not unlimited. Single HSCs can differentiate into neutrophils, lymphocytes, red cells and platelets, even though it has been believed that they do not differentiate into cells outside of the hematopoietic system. HSCs can also reconstitute all hematopoietic cell types when transplanted into lethally irradiated mice or humans.
In all these studies, fresh BM or PB cells were transplanted without prior in vitroculture, sothat the question of whether thecell with plasticity can undergo self-renewal could not be assessed. Furthermore, grafted cells were not retransplanted in secondary recipients precluding assessment of self-renewal of the cell with plasticity in vivo. Exceptions arethestudies by Krause et al. [29] and Grant \& al. [26], in which singlecells reestablished hematopoi esis, suggesting self-renewal of the HSC in vivo. Furthermore, in the study by Grant et al. [26], serial transplantations were performed to demonstrateself-renewal of the HSC.

Most studies transplanted mixed cell populations from wild-typeanimals, or animals transgenic for the $\beta$-galactosidasegene, which allows detection by X-Gal staining, or theenhanced green-fluorescent protein (eGFP) marker gene. Even in studies in which enriched HSC gave rise to both hematopoi etic cells and, for instance, liver epithelium [32], multiplecells were grafted. Therefore, the second criterion - singlecell multi-lineage differentiation - could not beassessed. This was not thecase for thereport by Krausee al. [29], in which single 'homed' $\mathrm{CD} 34^{+} \mathrm{Scal}^{+}$cells were transferred to secondary recipients, and differentiation into hematopoi etic and epithelial cells was shown. Likewise, in thestudy by Grant et al. [26], singleHSCs weretransplanted, and cells within endothelium of the retina and hematopoietic cells were shown to be derived from a single progenitor.

Most studies defined plasticity based on the acquisition of morphologic and phenotypic characteristics of thenon-hematopoietictissue. Because the degree of engraftment in non-hematopoi etic tissues was usually less than a few percent, acquisition of phenotypic characteristics alone, such as dystrophin expression and al bumin expression, cannot be used to provefunctional ity of theindividual grafted cells. Therefore, most studies al so did not fulfill thethird criterion of stem cells, namely functional differentiation in vivo. Notableexceptions are thestudy by Lagasseet al. [31] demonstrating functional replacement of hepatocytes following systemic injection of murineBM cells enriched for HSC. Theanimal model used was thehereditary tyrosinemia model, caused by deletion of the gene encoding fumarylacetoacetate hydrolase (FAH). This mutation is lethal, although animals - like humans - can bekept al ive by administration of 2-(2-nitro-4-fluoromethylbenzoyl)-1,3-cyclohexanedione (NTBC), which inhibits 4-hydroxyphenyl pyruvate di oxygenase, upstream of FAH. The only other therapy is replacement of hepatocytes by wild-type hepatocytes [32]. Lagasse et al. showed that animals transplanted with wild-typeBM or wild-type BM enriched for HSC could beweaned off NTBC, and that donor BM and HSC differentiated into cells with phenotypic characteristics of hepatocytes that must befunctional as they rescued the otherwise-lethal phenotype. In a study by Orlice al. [24], the investigators demonstrated in a murine model of myocardial ischemia, that grafting of enriched HSC in theinfarcted area leads to engraftment of BM-derived cells that acquire characteristics of immaturecardiomyoblasts. In addition, significant improvement in cardiacfunction was shown. Finally, in a study by Grant et al. [26], endothelial cells generated from singletransplanted HSC were functional as new capillaries wereformed following radiation-induced lesions of the retina.

Stem cell plasticity of mesenchymal bone marrow cells Asidefrom HSCs, BM also contains MSCs. MSCs can becultured ex vivofor several passages and differentiateat thesingle-cell level intolimb-bud mesodermal cell types, including osteoblasts, chondroblasts, adipocytes, fibroblasts and skeletal myoblasts [12-16]. When introduced in vivo, MSCs differentiate into thesamearray of cell types [33]. Several recent reports haveshown that MSCsmight acquirecharacteristics of cells outside the limb-bud mesoderm, including endothelium [34,35], neurœectoderm [35-37] and endoderm [35,38]. Because all studies using MSCs use cells cultured in vitro that have been passaged several times (for $>100$ cell doublings) $[13,15,16,35,38,39]$, they demonstrate that the cell with plasticity has self-renewal activity. Thestudy by J iang et al. [35] also showed that cells collected from initial transplant recipients could upon transfer to secondary recipients giverise to multiple cell types, suggesting in vivoself renewal behavior.

Toaddress the clonal derivation of differentiated progeny, somestudies have depended on ring-cloning to isolate progeny of singlecells $[15,16]$. However, this approach does not fully prove that singlecells give riseto multiple progeny as MSCs are very motile in cultureand several individual cells might therefore havecontributed tothecol ony that is isolated in a given ring. Other studies have used more fool proof single-cell sorting strategies [14] or retroviral 


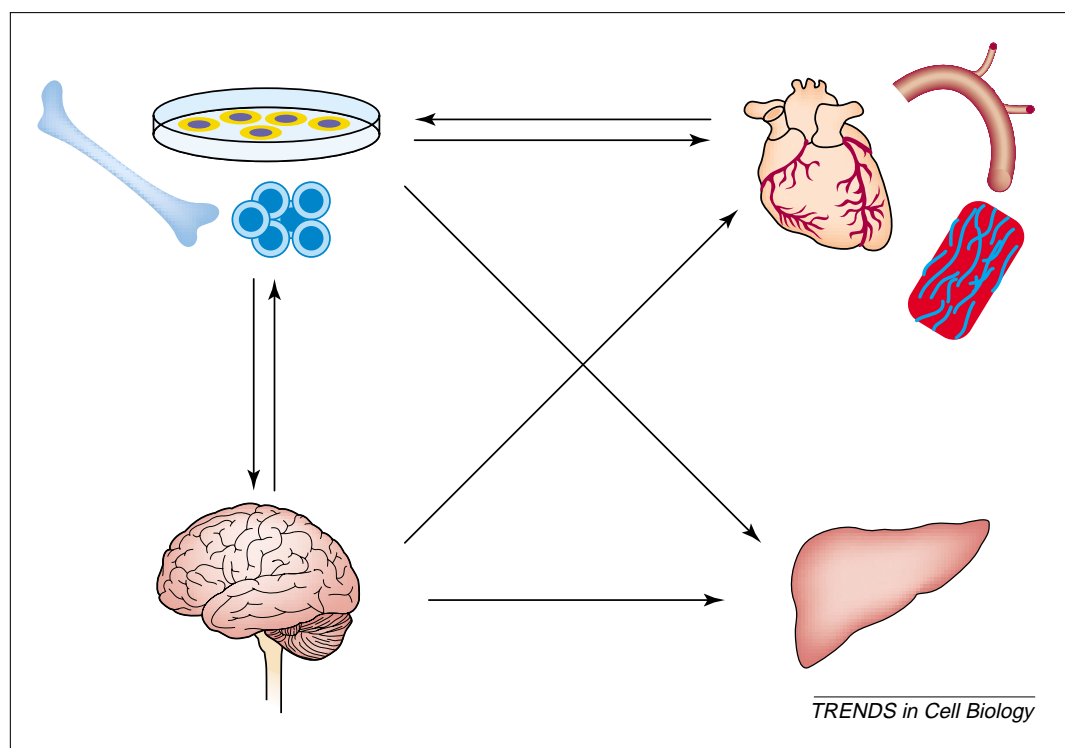

Fig. 2. Stem cell plasticity. Stem cell plasticity has been described as the unexpected potential of cells from bone marrow, muscle or brain to give rise to cells of tissues other than the tissue of origin. Examples include bone-marrow-derived cells or even purified hematopoietic stem cells that can give rise to endothelium, skeletal muscle, cardiac muscle or hepatocytes. marking strategies $[35,38,39]$ to demonstrate multi-lineage differentiation from singlecells.

Only a few studies have assessed function of differentiated cell s other than limb bud mesoderm lineagecells. Reyes et al. [34] showed that multipotent adult progenitor cells (MAPCs) differentiatein the presence of vascular endothelial growth factor into cells with endothelial morphology and phenotype and function likeendothelial cells in vitro and in vivo. Schwartz \& al. [38] showed that MAPCs, induced to differentiate to hepatocyte-likecells with fibroblast growth factor 4 and hepatocyte growth factor, secrete al bumin and urea and have phenobarbital-inducible cytochrome-p450 activity, all functional characteristics of hepatocytes. Even though several groups showed that MSCs can differentiate into cells with morphol ogical and phenotypic characteristics of glia and neurons [35-37], they have yet to show that these cells have el ectrophysiological characteristics of neurons. None of thestudies has shown that MSCs functionally repopulate damaged tissue outside of limb-bud mesodermal tissues following transplantation in vivo.

\section{Plasticity of skeletal muscle cells}

Asidefrom BM cell plasticity, plasticity has been reported for cells derived from other organs. $\mathrm{J}$ ackson et al. [40] reported that transplantation of musclecells or muscle side population cells (Sp), selected based on their ability to extrude Hoechst dye and cultured ex vivo for 2-3 days, could give riseto hematopoietic cells foll owing lethal irradiation, and could compete with BM-derived HSCs, a criterion commonly used to demonstratethe presence of functional HSCs [41]. However, not shown in this initial study was that thesamecell that gives riseto hematopoietic cells al so gives rise to myoblasts. Likewise, Gussoni et al. showed that muscleSp cells could reconstitutethehematopoi etic system in lethally irradiated mice [23]. However, a subsequent study by McKinney-Freeman et al. [42] and Kawada et al. [43] showed that this apparent plasticity might becaused by HSCs present in muscletissue. Thus, thesestudies do not demonstrate stem cell plasticity, even though a singletissueis capable of generating two different cell types - a phenomenon that could betermed tissueplasticity.

\section{Plasticity of neural cells}

Bjornson et al. [44] reported that murine NSCs cultured ex vivo for several population doublings could differentiateinto hematopoietic cells. Similar results were reported for human NSCs by Shih et al. [45]. Both studies used ex vivo cultured cells that had undergoneseveral cell doublings and therefore fulfill the first criterion of stem cells. Both used cell s generated from singleneural spheres, which arethought to be derived from a single NSC. However, they did not use retroviral marking or singlecell sorting to fully provethat the cells within a neural sphereweresingle-cell derived. Finally, although a large proportion of thehematopoietic cells were derived from theneural spheres, neither study demonstrated that these cells could rescueanimals from aplasia, nor did they use competitive repopulation assays to demonstrate the function of hematopoi etic cells in vivo. However, a third study, reported that thefrequency with which this lineage switch can occur for murine NSCs is at best extremely low [46].

Clarkeet al . also assessed the plasticity of NSCs [47]. Progeny of singlebrain-derived neural spheres were introduced either in thechick embryo or in themurine blastocyst. In both assays, they demonstrated that NSC progeny could contributeto multipletissues, even though some tissues appeared not to be derived from the NSCs, including, interestingly, the hematopoi etic system. LikeBjornson \& al. [44] and Shih et al. [45], Clarkeet al. used ex vivo cultured cells that had undergoneseveral cell doublings, and the cell with plasticity thereforefulfills thefirst criterion of stem cells. Singleneural sphere progeny wereused that were, however, not retrovirally marked or generated from single sorted cells tofully provethat thecells within a neural sphereweresingle-cell derived. Finally, none of the chimeric mice was born, which precludes assessment of thefunctional differentiation of thecells in vivo.

\section{Plasticity of other tissues}

Toma et al. described that cells isol ated from dermis of mouse and man can becultured ex vivo for several months and can differentiateinto cells with phenotypic characteristics of neurons and glial cells, as well as adi pocytes and smooth muscle, in vitro [48]. Single sorted cells were used to initiate the cultures. However, the differentiated cells were not functionally characterized, and in vivo repopulation studies were not performed.

Finally, thereare reports of plasticity within the endodermal lineage. Shen et al. [49] showed that a 
Fig. 3. Possible explanations for the perceived plasticity. (a) Stem cells for a given tissue might exist in an unrelated organ.

(b) Perceived plasticity might be caused by the transplanted cells fusing with a host cell of a different lineage, leading to transfer of the genetic information of the transplanted cell to the host-derived cell.

(c) Plasticity might occur via de- and re-differentiation, as is seen in cloning or in limb regeneration in amphibians. (d) Cells with pluripotent characteristics might persist even after the initial steps of embryological development.

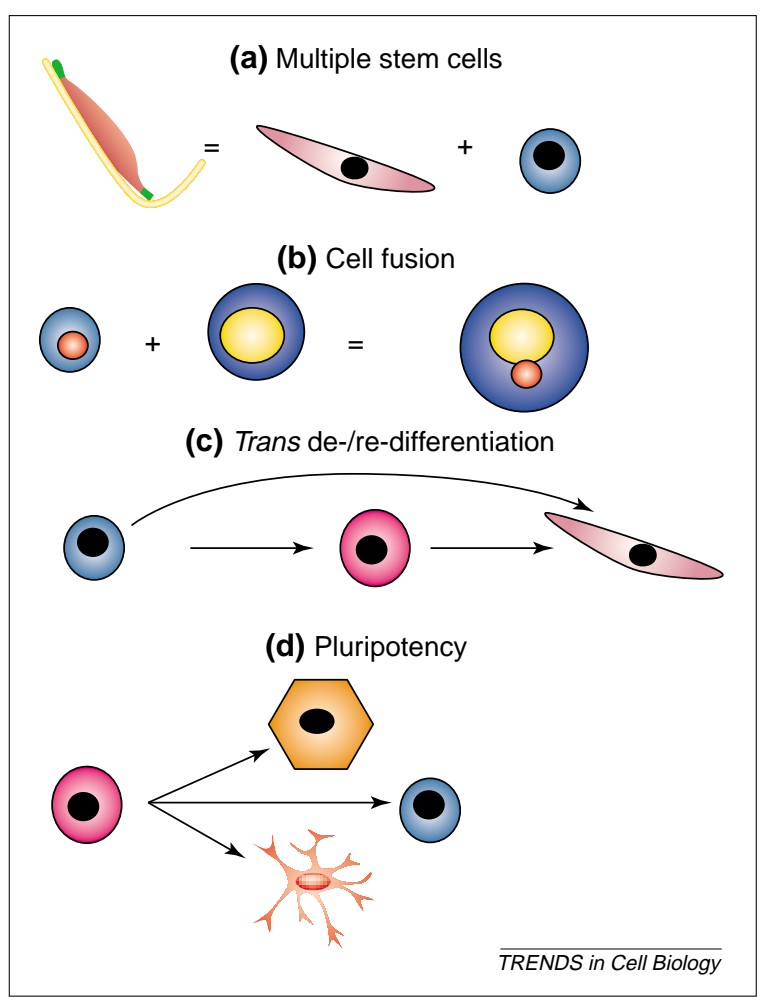

human pancreatic cell line as well as fetal pancreatic tissuecan be induced to acquire phenotypic characteristics of hepatocytes in vitro by treatment with dexamethasone or introduction of $C / E B P \beta$. This lineageswitch appeared to occur without interim cell division. However, nofunctional characterization was performed on the hepatocyte-likecells, and noproof exists that these hepatocyte-like cells functionally repopulatetheliver in vivo. Yang et al. showed that oval cells, the progenitor for hepatocytes and biliary epithelium, can be cultured ex vivo for prolonged periods of time, and can beinduced to express insulin. Thesecells reverse gl ucose intolerance when transplanted in vivo in a streptozotocin-treated mouse[50]. However, as the transplanted tissue was not removed to demonstrate that the reversal in insulin dependence was caused by the graft rather than incomplete ablation of endogenous $\beta$ cells, additional studies will berequired to fully provethat thelineage switch generated functional $\beta$ cells.

\section{Possible explanations for perceived plasticity} At least four different explanations exist for the perceived plasticity described in thestudies discussed above(Fig. 3). First, it is clear that stem cells for a given tissuemight exist in unrelated tissues ( $\mathrm{Fig}$. 3a). This has been el egantly shown for HSCs in muscle [42,43], and also has been shown for oval cells in BM [51]. In this instance, the apparent lineageswitch is not caused by a singlestem cell that can alter its differentiation behavior; rather, the presence of multiple stem cells gives theimpression of plasticity.

Second, the perceived plasticity might becaused by the transplanted cells fusing with a host cell of a different lineage, leading totransfer of the genetic information of thetransplanted cell to thehost-derived cell (Fig. 3b). This phenomenon underlying the heterokaryon technique was described many decades ago [52] and was more recently demonstrated to occur between ES cells and somatic cells. In two independent studies, coculture of ES cells with cells derived from adult tissueresulted in fusion of the ES cell with an adult cell, in which thegenetic information in the ES cell is transferred to theadult cell $[53,54]$. This phenomenon was rare ( $1 / 10^{5}-10^{6}$ cells), occurred in the presence of significant selectable pressure, and the resulting cells weretetrapl oid. However, no published study dealing with plasticity has proven that the observed trans-differentiation is not caused by this phenomenon. Circumstances wherethis mechanism might be morelikely includeconditions where extensiveselectable pressure is needed to see the plasticity of stem cells, where plasticity is seen in tissues that 'tolerate' tetraploidy, such as muscle, hepatocytes, Purkinjecells and others, and wherethe frequency of trans-differentiation is low. However, it is important tokeep in mind that, although the studies by Ying et al. and Terada et al. reminded the scientific community of this possibility $[53,54]$, neither study showed that such a cell fusion phenomenon occurs in vivo, where most of the plasticity phenomena have been described.

Third, since the doning of Dolly [55], a large body of evidence has been created indicating that an adult cell from many mammalian species $[56,57]$ can be reprogrammed to acquirea pluripotent fatewhen the nucleus is introduced into the cytoplasm of a non-fertilized egg. De-differentiation and re-differentiation is also thought to underliethe ability of amphibians and fish to regeneratelimbs spontaneously. Therefore, the perceived plasticity might occur via de and re-differentiation or via nuclear reprogramming (Fig. 3c). Under this scenario, stem cells, progenitor cells or even more-differentiated cells would undergo genetic reprogramming when removed from their usual 'niche' and introduced into a different microenvironmental niche. F actors in egg cytoplasm that reprogram the nud eus of the somatic donor cell during nuclear transplantation are not known. Insights intothemolecular mechanisms underlying nud ear reprogramming might ther efore help our understanding of adult stem cell plasticity and might beexploited in thefuturetoinducelineage switching even without nuclear transplantation. Likewise, the exact mechanisms that underlielimb regeneration in amphibians and fish are not fully understood. It is believed that, upon loss of a limb, 'terminally differentiated' cells in the blastema de-differentiateand then re-differentiate to generate the many different cell types required for creation of a new limb. Signaling via retinoic acid receptors [58] and Sonic Hedgehog (Shh) [59] is thought to play a rolein the genetic reprogramming required for this phenomenon to occur. Specific homeobox genes have 
been characterized that play a role in this de-and redifferentiation event [60]. For example, M sxl can induce a similar de-differentiation event when introduced in mammalian cell lines [61]. Whether any of the de-and re-differentiation pathways that have been identified in fish and amphibians play a rolein higher mammalian stem cell plasticity will need to bedefined.

Finally, cells with pluripotent characteristics might persist even after the initial steps of embryol ogical development (Fig. 3d). Pluripotent ES cells are characterized at the mol ecular level by the transcription factor oct-4 [62-64], which is expressed in the pre-gastrulation embryo, early cleavage-stage embryo, cells of theinner cell mass of theblastocyst and in embryonic carcinoma cells. Oct- 4 is downregulated when cells are induced to differentiate in vitro [65], and, in theadult animal, oct-4 is found only in germ cells. Several studies haveshown that Oct- 4 is required for maintaining the undifferentiated phenotype of ES cells and plays a major rolein determining early steps in embryogenesis and differentiation $[62,66]$. Another hallmark of ES cells is the presence of telomerase [67,68], which all ows ES cells to undergo unlimited cell divisions. One might therefore cond udethat, for a stem cell to be pluripotent, someor all of thesecharacteristics should be present. Except for MAPCs described in the study by j ianget al. [35], whoshowed that murine MAPCs express - al beit at low levels - oct- 4 and the stage-specificembryonic antigen SSEA-1, noadult somatic cell has been described that expresses these characteristics. However, as it remains to be determined whether MAPCs exist as such in vivo or aretheresult of de-differentiation of an MSC-like cell into a cell with greater potential, thereis currently no definitive proof that true pluripotent stem cells exist in vivo during post-natal life. Studies aimed at proving or disproving their existencearenot only of scientific importance but will havefar-reaching implications for use of the plasticity phenomenon in clinical medicine.

Can adult stem cells be used for therapeutic purposes? Hematopoietic stem cells from BM, blood or umbilical cord blood have been used dinically to re-establish the hematopoietic system following radiation and/or chemotherapy for the past threedecades. More recently, use of epidermal stem cells and corneal stem cells is being explored in the dinic, and a large number of studies haveevaluated, in pre-clinical models, the use of NSCs to correct defects of the central nervous system and spinal cord.

Several studies haveassessed whether BM or peripheral blood cells might contributetotissues other than thehematopoieticsystem in theclinical setting. Results from thesestudies aremixed. Even in the 1980s, several groups tested whether non-hematopoietic stromal cells within theBM were donor derived after BM transplantation. Some studies suggested that stromal cells were donor in origin [69], whereas others contradicted this notion [70], and a more recent study evaluating patients more than 10 years after transplant concluded that stromal cells might not bereplaced by donor cells [78]. Along the same lines, Horwitz \& al. [71] reported that donor marrow transplanted into patients with osteogenesis imperfecta might ameli orate bonebrittleness, presumably because mesenchymal cells engrafted. As no evidence was provided that donor osteoblasts were present, it remains to be determined whether clinical improvement was duetoreplacement of existing osteoblasts with donor cells.

\section{'Although stem cell plasticity is not fully proven, there is sufficient evidence to warrant continued efforts to prove or disprove that some adult stem cells might be more pluripotent...'}

Subsequently, several studies have shown that human BM cell or cells circulating in the blood might contributeto many different tissues. Theiseet al. [72] reported that donor-derived cells that appear to have differentiated into hepatocytes can be detected in the liver of patients who devel op liver damage following BM transplantation. Likewise, in patients that underwent orthoptic liver transplantation, host-derived cells with apparent hepatocyte features could be detected in the donor liver. Korbling et al. [73] reported that up to $7 \%$ of hepatocytes and epithelial cells of theskin and gastrointestinal tract in patients that had undergoneal logeneic sex-mismatched peripheral blood grafts might be derived from the graft. Of note, in both studies, donor-derived epithelial cells were usually found as singlecells - and not as clusters of cells, as one might expect for donor cells trans-differentiating into epithelial stem cells that then proliferate locally and differentiateto forma col ony of donor cells. This notion is consistent with the study by Hematti \& al. [79], who showed that, although up to $14 \%$ of keratinocytes in the skin of patients that underwent donor HSC transplantations are donor derived, keratinocytestem cells remain host in origin. This study indicates ther eforethat further studies will be needed to determine whether the phenomenon of adult stem cell plasticity will be applicabletoregenerative medicine as this will require trans-differentiation to a stem cell phenotype and not to a maturecell phenotype.

Quaini et al. [74] reported that between $12 \%$ and $16 \%$ of cardiac myocytes might behost derived in patients undergoing orthoptic heart transplantation. However, threesubsequent studies [75-77] have suggested that cardiomyocytes of noncardiac origin in transplanted hearts areat best extremely rare (in the 
range of $0.1-0.01 \%$ ), even in the setting of significant cardiac damagein the setting of rejection. Such levels of contribution would not be dinically useful.

Although the discussion above indicates that stem cell plasticity is not proven, there is sufficient evidenceto warrant continued efforts to prove or disprove that someadult stem cells might bemore pluripotent as this would open the door tothe use of stem cells from one organ, such as bonemarrow or circulating in the blood, to correct genetic or degenerative disorders of a second organ from which stem cells aremore difficult to isolate, such as brain.

Onequestion to beaddressed will be whether the mechanism underlying the perceived plasticity matters when considering clinical application of adult stem cells. Onemight argue that even if liver regeneration from BM $[30,31]$ wereto be derived from a hepatic stem cell or oval cell co-existing with HSC in BM, BM cells might still bean excellent source of cells totreat liver failureas long as robust and persistent engraftment could be shown. This would however not qualify as stem cell plasticity. Perhaps, if perceived plasticity was dueto fusion of a donor cell with an existing tissue cell, this might still beuseful totreat tissues consisting of multinucl eated cells, such as skeletal muscle. Then, if BM cells could beinduced to fuse in high frequency with skeletal myoblasts, this might form a novel gene-therapy approach for muscular dystrophy, provided that the fused progeny wereotherwisenormal.

However, for adult stem cell plasticity to be clinically useful on a large scale, a ready supply of well-characterized 'pl uripotent' adult stem cells will be required. If pluripotency is acquired by ex vivo mani pulation which caused de-differentiation, then defining the molecular mechanism(s) underlying the lineage switching will be required to enhance the frequency and fidelity with which this event occurs. One caveat that will need to beaddressed is whether the process of de and redifferentiation al ways occurs without causing unwanted genetic abnormalities that might lead to aberrant differentiation or might even be oncogenic. If pluripotent stem cells indeed exist in vivo, better characterization of the phenotype of such cells, their natural environment and proliferation and/or differentiation behavior, and their ability to be recruited to areas of injury, will be important to exploit their clinical usefulness. In addition, it will behove scientists and clinicians aliketotest whether re-activation of presumed quiescent pluripotent stem cells by ex vivo culture or by in vivo manipulation will not cause uncontrol lable prol iferation and/or differentiation similar toteratomas, seen when ES cells aretransplanted in vivo.

Some would arguethat one of the major advantages of adult stem cells is that they might beharvested from the patient and avoid unwanted immuneresponses. However, becausethemechanism(s) underlying a variety of degenerativedisorders arecurrently not known, it remains to be determined whether similar defects might be present in stem cells or their progeny from an individual afflicted by these disorders. Second, although autologous stem cell therapy might well be suitabletotreat chronic disorders, such as Parkinson's disease, such therapy might not beavailablein a timely manner to correct acute injuries, such as myocardial infarcts, cerebral ischemia and spinal cord injury, if preclinical models demonstratethat thetherapy is most efficacious when given shortly after theinjury.

\section{Concluding remarks}

Despitetheever-growing number of studies suggesting that pluripotent stem cells can be obtained from adult tissues and that certain cells might have the capacity to acquire a more pluripotent state, the field of stem cell plasticity is in its infancy. Indeed, the evidence that pluripotency exists or can bere-induced is not yet conclusive. Becausesomeinitial reports have since been reinterpreted, as the majority of studies still await independent confirmation and as the possible mechanisms underlying the perceived plasticity are not understood, thescientific community has looked upon this field with healthy skepticism. Investigators studying plasticity will need to assess findings of plasticity in light of the definition commonly accepted to definestem cells - that is, demonstrate that singlecells derived from adult tissuedifferentiate into multiplelineages characterized not only based on phenotype but al so on function and support robust, sustained and functional multilineage engraftment in vivo. Notwithstanding theskepticism, this is an exciting timeto beinvol ved in stem cell research, with great challenges and al so great expectations ahead.

\section{References}

1 Weissman, I.L. (2000) Translating stem and progenitor cell biology to the dinic: barriers and opportunities. Science287, 1442-1446

2 Martin, G.R. (1981) I solation of a pluripotent cell linefrom early mouseembryos cultured in medium conditioned by teratocarcinoma stem cells. Proc. Natl. Acad. Sci. U. S. A. 78, 7634-7638

3 Evans, M.J . and Kaufman, M.H. (1981) Establishment in culture of pluripotential cells from mouseembryos. Nature292, 154-156

4 Thomson, J .et al. (1995) I solation of a primate embryonic stem cell line. Proc. Natl. Acad. Sci. U.S. A. $92,7844-7848$
5 Thomson, J .A. et al. (1998) Embryonic stem cell lines derived from human blastocysts. Science 282, 1145- 1147

6 Nagy, A. etal. (1993) Derivation of completely cell culture-derived mice from early-passage embryonic stem cells. Proc. Natl. Acad. Sci. U.S. A. $90,8424-8428$

7 Spangrude, G. et al . (1988) Purification and characterization of mousehematopoietic stem cells. Science241, 58

8 Bhatia, M. etal. (1997) Purification of primitive human hematopoietic cells capable of repopulating immune-deficient mice. Proc. Natl. Acad. Sci. U. S. A. 94 5320-5325
9 Ogawa, M. et al. (1996) Long-term Iymphohematopoi etic reconstitution by a single 34-low/negative hematopoietic stem cell. Science $273,242-245$

10 McKay, R. (1997) Stem cells in the central nervous system. Science 276, 66-71

11 Gage, F.H. (2000) Mammalian neural stem cells. Science287, 1433-1438

12 Fridenshtein, A. (1982) Stromal bonemarrow cells and the hematopoi etic microenvironment. Arkh. Patol. 44, 3-11

13 Haynesworth, S.E. et al. (1992) Cell surface antigens on human marrow-derived mesenchymal cells are detected by monoclonal antibodies. Bone13, 69-80 
14 Gronthos, S. and Simmons, P. (1996) The biology and application of human bonemarrow stromal cell precursors. J . Hematother. 5, 15-23

15 Prockop, D. (1997) Marrow stromal cells as stem cells for nonhematopoietic tissues. Science276, 71-74

16 Pittenger, M.F. et al. (1999) Multilineage potential of adult human mesenchymal stem cells. Science 284, 143-147

17 Watt, F.M. (2001) Stem cell fateand patterning in mammalian epidermis. Curr. Opin. Genet. Dev. $11,410-417$

18 Daniels, J .T. et al. (2001) Corneal stem cells in review. Wound Repair Regen. 9, 483-494

19 Rafii, S. etal. (1994) I solation and characterization of human bonemarrow microvascular endothelial cells: hematopoietic progenitor cell adhesion. Blood 84, 10

20 Wulf, G.G. et al. (2001) Somatic stemcell plasticity: current evidence and emerging concepts. Exp. Hematol. 29, 1361-1370

21 Tisdale, J .F. and Dunbar, C.E. (2002) Plasticity and hematopoiesis: Circe's transforming potion? Curr. Opin. Hematol. 9, 268-273

22 Ferrari, G. et al. (1998) Muscleregeneration by bone marrow-derived myogenic progenitors. Science279, 1528-1530

23 Gussoni, E. et al. (1999) Dystrophin expression in the mdx mouse restored by stem cell transplantation. Nature 401, 390-394

24 Orlic, D. etal. (2001) Bonemarrow cells regenerate infarcted myocardium. Nature410, 701-705

25 J ackson, K. et al. (2001) Regeneration of ischemic cardiac muscleand vascular endothelium by adult stem cells. J . Clin. Invest. 107, 1395-1402

26 Grant, M.B. et al. (2002) Adult hematopoietic stem cells provide functional hemangioblast activity during retinal neovascularization. Nat. Med. 8, 607-612

27 Mezey, E. et al. (2000) Turning blood into brain: cells bearing neuronal antigens generated in vivo from bonemarrow. Science290, 1779-1782

28 Brazelton, T.R. et al . (2000) From marrow to brain: expression of neuronal phenotypes in adult mice. Science290, 1775-1779

29 Krause, D.S. etal. (2001) Multi-organ, multi-lineage engraftment by a single bone marrow-derived stem cell. Cell 105, 369-377

30 Petersen, B.E. et al. (1999) Bonemarrow as a potential source of hepatic oval cells. Science284, 1168-1170

31 Lagasse, E. et al. (2000) Purified hematopoietic stem cells can differentiateinto hepatocytes in vivo. Nat. Med. 6, 1229-1234

32 Grompe, M. (1999) Therapeutic liver repopulation for thetreatment of metabolicliver diseases. Hum. Cell 12, 171-180

33 Liechty, K.W. et al. (2000) Human mesenchymal stem cells engraft and demonstratesite-specific differentiation after in uterotransplantation in sheep. Nat. Med. 6, 1282-1286

34 Reyes, M. et al. (2002) Origin of endothelial progenitors in human post-natal bonemarrow. J . Clin. Invest. 109, 337-346

35 J iang, Y. etal. (2002) Pluripotent nature of adult marrow derived mesenchymal stem cells. Nature $418,41-49$

36 Kopen, G. et al. (1999) Marrow stromal cells migratethroughout forebrain and cerebellum, and they differentiateinto astrocytes after injection into neonatal mousebrains. Proc. Natl. Acad. Sci. U. S. A. 96, 10711-10716
37 Woodbury, D. et al. (2000) Adult rat and human bonemarrow stromal cells differentiateinto neurons. J . Neurosci. Res. 61, 364-370

38 Schwartz, R.E. etal. (2002) Multipotent adult progenitor cells from bonemarrow differentiate intofunctional hepatocytelikecells. J . Clin. Invest. 109, 1291-1302

39 Reyes, M. et al. (2001) Purification and ex vivo expansion of postnatal human marrow mesodermal progenitor cells. Blood 98, 2615-2625

40 J ackson, K. et al. (1999) Hematopoietic potential of stem cells isol ated from murine skeletal muscle. Proc. Natl. Acad. Sci. U. S. A. 96, 14482-14486

41 Szilvassy, S.J . etal. (1990) Quantitativeassay for totipotent reconstituting hematopoietic stem cells by a competitive repopulation strategy. Proc. Natl. Acad. Sci. U. S. A. 87, 8736-8740

42 McKinney-Freeman, S.L. et al. (2002) Muscle-derived hematopoietic stem cells are hematopoieticin origin. Proc. Natl. Acad. Sci. U.S. A. $99,1341-1346$

$43 \mathrm{Kawada}, \mathrm{H}$. and Ogawa, M. (2001) Bonemarrow origin of hematopoietic progenitors and stem cells in murine muscle. Blood 98, 2008-2013

44 Bjornson, C. et al. (1999) Turning brain into blood: a hematopoietic fate adopted by adult neural stem cells in vivo. Science283, 354-357

45 Shih, C.C. et al. (2001) I dentification of a candidatehuman neurohematopoietic stem-cell population. Blood 98, 2412-2422

46 Morshead, C.M. et al. (2002) Hematopoietic competence is a rare property of neural stem cells that may depend on genetic and epigenetic alterations. Nat. Med. 8, 268-273

47 Clarke, D.L. et al. (2000) Generalized potential of adult neural stem cells. Science288, 1660-1663

48 Toma, J .G. et al. (2001) I solation of multipotent adult stem cells from the dermis of mammalian skin. Nat. Cell Biol. 3, 778-784

49 Shen, C.N. et al. (2000) Molecular basis of transdifferentiation of pancreas toliver. Nat. Cell Biol. 2, 879-887

50 Yang, L. et al. (2002) In vitrotrans-differentiation of adult hepatic stem cells into pancreatic endocrine hormone-producing cells. Proc. Natl. Acad. Sci. U. S. A. 99, 8078-8083

51 Mitaka, T. (2001) Hepatic stem cells: from bone marrow cells to hepatocytes. Biochem. Biophys. Res. Commun. 281, 1-5

52 Kikyo, N. and Wolffe, A.P. (2000) Reprogramming nuclei: insights from cloning, nuclear transfer and heterokaryons. J . Cell Sci. 113, 11-20

53 Terada, N. et al. (2002) Bonemarrow cells adopt the phenotype of other cells by spontaneous cell fusion. Nature 416, 542-545

54 Ying, Q.Y. etal. (2002) Changing potency by spontaneous fusion. Nature416, 545-548

55 Campbell, K.H. et al. (1996) Sheep cloned by nuclear transfer from a cultured cell line. Nature $380,64-66$

56 Wakayama, T. etal. (1998) Full-term development of micefrom enucleated oocytes injected with cumulus cell nuclei. Nature394, 369-374

57 Rideout, W.M.R. etal. (2001) Nuclear cloning and epigenetic reprogramming of the genome. Science 293, 1093-1098

58 Maden, M. (1998) Retinoids as endogenous components of the regenerating limb and tail. Wound Repair Regen. 6, 358-365
59 Imokawa, Y. and Yoshizato, K. (1998) Expression of sonic hedgehog genein regenerating newt limbs. Wound Repair Regen. 6, 366-370

60 Brockes, J .P. (1997) Amphibian limb regeneration: rebuilding a complex structure. Science 276, 81-87

61 Odelberg, S.J . et al. (2000) Dedifferentiation of mammalian myotubes induced by msx1. Cell 103, 1099-1109

62 Nichols, J . et al. (1998) Formation of pluripotent stem cells in the mammalian embryo depends on the POU transcription factor Oct4. Cell 95, 379-391

63 Scholer, H.R. et al. (1989) A family of octamer-specific proteins present during mouse embryogenesis: evidence for germline-specific expression of an Oct factor. EMBO J .8, 2543-2550

64 Rosner, M.H. etal. (1990) A POU-domain transcription factor in early stem cells and germ cells of the mammalian embryo. Nature345, 686-692

65 Pikarsky, E. et al. (1994) Retinoic acid represses Oct-3/ 4 geneexpression through several retinoic acid-responsive elements located in the promoterenhancer region. Mol. Cell. Biol. 14, 1026-1038

66 Niwa, H. et al. (2000) Quantitativeexpression of Oct-3/4 defines differentiation, dedifferentiation or self-renewal of ES cells. Nat. Genet. 24, 372-376

67 Greider, C. (1998) Telomeres and senescence: the history, the experiment, thefuture. Curr. Biol. 8 , 178-181

68 Hodes, R.J . (1999) Telomerelength, aging, and somatic cell turnover. J . Exp. Med. 190, 153-156

69 Keating, A. et al. (1982) Donor origin of thein vitro haematopoietic microenvironment after marrow transplantation in man. Nature298, 280-283

70 Simmons, P.J . et al. (1987) Host origin of marrow stromal cells foll lowing all ogeneic bone marrow transplantation. Nature328, 429-432

71 Horwitz, E.M. et al. (1999) Transplantability and therapeutic effects of bonemarrow-derived mesenchymal cells in children with osteogenesis imperfecta. Nat. Med. 5, 309-315

72 Theise, N.D. et al. (2000) Liver from bonemarrow in humans. Hepatol ogy 32, 11-16

73 Korbling, M. et al. (2002) Hepatocytes and epithelial cells of donor origin in recipients of peripheral-blood stem cells. N. Engl. J . Med. 346, 738-746

74 Quaini, F. et al. (2002) Chimerism of the transplanted heart. N. Engl.J . Med. 346, 5-15

75 Muller, P. et al. (2002) Cardiomyocytes of noncardiac origin in myocardial biopsies of human transplanted hearts. Circulation 106, 31-35

76 Glaser, R. et al. (2002) Smooth musclecells, but not myocytes, of host origin in transplanted human hearts. Circulation 106, 17-19

77 Laflamme, M.A. et al. (2002) Evidencefor cardiomyocyterepopulation by extracardiac progenitors in transplanted human hearts. Circ. Res. 90, 634-640

78 Awaya, N. etal. (2002) Failure of adult marrow-derived stem cells to generatemarrow stroma after successful hematopoietic stem cel transplantation. Exp. Hematol. 30, 937-942

79 Hematti, P. et al. (2002) Absence of donor-derived keratinocytestem cells in skin tissues cultured from patients after mobilized peripheral blood hematopoietic stem cell transplantation. Exp. Hematol. 30, 943-949 